\title{
Molecular epidemiology of Pseudomonas aeruginosa infections in a cystic fibrosis outpatient clinic
}

\author{
LUIZ V.F. DA SILVA FILHO, JOSÉ E. LEVI*, CHRISTINA N.O. BENTO†, JOAQUIM C. RODRIGUES \\ and SÔNIA R.T. DA SILVA RAMOS
}

Instituto da Criança, Hospital das Clínicas, * Laboratory of Virology, Instituto de Medicina Tropical de São Paulo and + Microbiology Section of the Central Laboratory, Hospital das Clínicas, University of São Paulo Medical School (FMUSP), São Paulo, SP, Brazil

\begin{abstract}
Chronic respiratory infection by Pseudomonas aeruginosa is a significant determinant in the prognosis of cystic fibrosis patients. Cross-infection between cystic fibrosis patients and the prevalence of $P$. aeruginosa among them were investigated by microbiological surveillance and RAPD typing of the isolates. A total of 748 samples was cultured, including specimens from the respiratory tract (sputum or throat swabs) and hands of patients and medical staff, resulting in the collection of 86 isolates of $P$. aeruginosa from 65 samples. Prevalence of $P$. aeruginosa was $39.3 \%$ in respiratory samples, $0.2 \%$ on patients' hands and none in the medical staff's hand samples. RAPD typing characterised 51 genotypes and clonal persistence was observed in the majority of patients. These results suggest that cross-infection is not common in the outpatient clinic studied and a common source of acquisition is unlikely.
\end{abstract}

\section{Introduction}

Cystic fibrosis (CF) is the most common lethal genetic disease in Caucasians and is characterised by chronic and recurrent lung infections, pancreatic insufficiency and high chloride levels in the sweat. Chronic respiratory infections in these patients are usually due to Pseudomonas aeruginosa; its persistence is associated with the production of alginate, a polymer that protects the micro-organisms against host defences and amplifies the inflammatory response in the airways [1]. Therefore, lung disease is manifested as chronic endobronchitis related to the presence of mucoid $P$. aeruginosa strains that are seldom eradicated once established in the airways of these patients, even with aggressive antibiotic treatment $[1,2]$.

The acquisition of chronic $P$. aeruginosa infection has a major impact on prognosis because it is usually followed by progressive deterioration of lung function [3]. Considering the complexity of this disease, treatment in specialised centres is required and there has been concern about cross-infection between pa-

Received 17 March 2000; revised version accepted 11 August 2000.

Corresponding author: Dr L.V.F. da Silva Filho (e-mail: vicres@usp.br). tients in the last two decades, particularly with the emergence of multiresistant $P$. aeruginosa and Burkholderia cepacia strains [4-8]. With the objective of preventing the dissemination of these organisms, several CF centres have adopted infection control measures, which include outpatient and inpatient cohorting by colonisation status, infection control measures at the pulmonary function test laboratories and patient education $[9,10]$.

Infection control measures have also led to the need to develop adequate techniques for strain typing, because antibiotic susceptibility and other phenotyping methods such as serotyping are not reliable for epidemiological studies. Molecular typing methods, such as DNA macro-restriction or PCR-derived techniques, have emerged as the most efficient tools for strain discrimination [11-13]. Random amplified polymorphic DNA (RAPD) typing [14] is a PCR-based method with high discriminatory power used previously for strain typing $[13,15,16]$.

In Brazil, $\mathrm{CF}$ is an underdiagnosed condition that is primarily treated at specialised centres, usually university hospitals. The Paediatric Pulmonology Outpatient Clinic of the Instituto da Criança (Children's Institute of the Clinics Hospital - University of São Paulo Medical School) is a general paediatric pulmo- 
nology clinic that treats c. $120 \mathrm{CF}$ patients. Sporadic cases of infection with multiresistant $P$. aeruginosa strains have been identified, but usually in unrelated patients. Considering the substantial role of $P$. aeruginosa in the lung disease of these patients, the possibility of cross-infection between $\mathrm{CF}$ patients was assessed and the prevalence of $P$. aeruginosa among them was determined by microbiological surveillance and RAPD typing of isolates.

\section{Patients and methods}

\section{Patients}

Ninety-six CF patients (47 male and 49 female; aged 9 months-19 years, mean age 8.46 SD 3.01 years) receiving treatment at the $\mathrm{CF}$ Outpatient Clinic of the Instituto da Criança were studied from Jan. to July 1996. Diagnosis of CF was based on clinical symptoms and two positive sweat tests. The clinic is a general paediatric pulmonology clinic with four offices with a shared corridor and a large waiting room, and $\mathrm{CF}$ patients are seen 3 days a week during the morning.

\section{Samples}

Samples of sputum or throat swabs and hand swabs of patients and medical staff were collected by one of the investigators (L.V.F. da S.F.) at each patient visit. Sputum or throat swabs were collected before swabbing patients' hands. Sputum samples were collected directly by expectoration in to a sterile plastic receptacle and throat swabs were collected by direct friction of a sterile cotton swab on the posterior pharynx, if possible after coughing and with use of a tongue depressor. Swabbing of the hands of medical staff was always performed after physical examination of the patient, without guidance or information regarding hand washing. Each sample collected was identified with a number and a letter (' $A$ ' for sputum or throat swabs, ' $B$ ' for patients' hand swabs and ' $C$ ' for medical staff hand swabs) and sent to the microbiology laboratory for culture within $4 \mathrm{~h}$. Written informed consent was obtained from the patients' parents, accompanied by responses to a questionnaire about social contact with other patients. The Ethical Committee of the Institution approved the study.

\section{Previous colonisation data}

Data on previous colonisation were obtained by retrospective analysis of medical records. Chronic colonisation was defined as at least three cultures with isolation of $P$. aeruginosa in the last 6 months; intermittent colonisation was defined as positive cultures in the last year, but not fulfilling the criteria for chronic colonisation outside of the chronic criteria, and not colonised was defined as negative cultures in the last year (with at least two cultures collected). Serum precipitins were not determined.

\section{Cultures}

Samples were initially inoculated in to Thioglycollate Broth (Difco), incubated at $35^{\circ}-37^{\circ} \mathrm{C}$ for $24 \mathrm{~h}$, then sub-cultured on selective medium (Bacto Cetrimide Agar Base; Difco) and incubated for $24 \mathrm{~h}$ at $35^{\circ}-37^{\circ} \mathrm{C}$. Suspected isolates of $P$. aeruginosa were identified by standard test procedures with the GNI card, VITEK system (bioMérieux Vitek, Hazelwood, MO, USA) and additional biochemical tests when necessary. Bacterial growth was not quantified. All $P$. aeruginosa isolates were tested for their susceptibilities to antibiotics by the disk diffusion agar method as standardised by the National Committee for Clinical Laboratory Standards [17]. The following antimicrobial disks $(\mu \mathrm{g})$ were used: amikacin 30, carbenicillin 100, cefoperazone 30, cefotaxime 30 , ceftazidime 30 , ceftriaxone 30 , gentamicin 10 , imipenem 10 , pefloxacin 5 , ciprofloxacin 5 , aztreonam 30 .

Results were recorded after incubation for $24 \mathrm{~h}$ at $37^{\circ} \mathrm{C}$. Strains resistant to all of the agents in two or more of the following antimicrobial categories were defined as multiresistant: $\beta$-lactam antibiotics including imipenem and aztreonam, aminoglycosides, and the fluoroquinolone ciprofloxacin, or all of these [18].

\section{DNA extraction}

DNA was extracted from $P$. aeruginosa isolates by the proteinase K-phenol-chloroform method [19] with bacterial colonies suspended in 500- $\mu \mathrm{l}$ mixtures consisting of proteinase $\mathrm{K}$ (Gibco-BRL Gaithersburg, FL, USA) $200 \mu \mathrm{g} / \mathrm{ml} ; 50 \mathrm{mM}$ Tris, $\mathrm{pH} 8.0$ and SDS $0.5 \%$. The mixture was incubated at $65^{\circ} \mathrm{C}$ for $2 \mathrm{~h}$ and then boiled for $10 \mathrm{~min}$. This was followed by two steps of organic extraction with phenol-chloroform and DNA precipitation with 2.5 volumes of cold ethanol and 0.1 volume of $3 \mathrm{M}$ sodium acetate $(\mathrm{pH}$ 5.2). The pellet was dried and suspended in sterile water, and DNA was quantified in a UV spectrophotometer (GeneQuant, Pharmacia, Uppsala, Sweden).

\section{$R A P D$ reactions}

RAPD was performed as described previously [13] in $25-\mu 1$ mixtures consisting of $10 \mathrm{mM}$ Tris $\mathrm{HCl}(\mathrm{pH} \mathrm{8.0)}$, $3 \mathrm{mM} \mathrm{MgCl}_{2}, 50 \mathrm{mM} \mathrm{KCl}$, containing $40 \mathrm{ng}$ of template DNA, $1.6 \mu \mathrm{M}$ of primer 272 (5'-AGCGGGC CAA-3'), $250 \mu \mathrm{M}$ of each dNTP and Taq DNA polymerase (Gibco-BRL) 1 U. Amplification was performed as follows: four cycles of $94^{\circ} \mathrm{C}$ for $5 \mathrm{~min}, 36^{\circ} \mathrm{C}$ for $5 \mathrm{~min}$ and $72^{\circ} \mathrm{C}$ for $5 \mathrm{~min} ; 30$ cycles of $94^{\circ} \mathrm{C}$ for $1 \mathrm{~min}, 36^{\circ} \mathrm{C}$ for $1 \mathrm{~min}, 72^{\circ} \mathrm{C}$ for $1 \mathrm{~min}$; and $72^{\circ} \mathrm{C}$ for $10 \mathrm{~min}$. RAPD products were visualised in agarose $1.5 \%$ gels stained with ethidium bromide $0.5 \mu \mathrm{g} / \mathrm{ml}$ with a UV transilluminator. RAPD patterns were determined by visual inspection. RAPD products between $100 \mathrm{bp}$ and $2 \mathrm{~kb}$ with intensities such that 
they were reproducible in two or more reactions were used for comparison between isolates.

\section{Statistical analysis}

Mucoid and non-mucoid strain susceptibility to antibiotics was compared with $\chi^{2}$ Yates corrected or Fisher's two-tailed exact tests. Comparisons between age groups and $P$. aeruginosa isolation in respiratory samples were performed by the $\chi^{2}$ test.

\section{Results}

A total of 748 samples (135 sputum, 119 throat swabs, 254 swabs of patients' hands, 240 hand swabs from medical staff) was cultured. P. aeruginosa was isolated from 65 samples (Table 1). P. aeruginosa was isolated from at least one sample from 38 patients $(39.5 \%)$. The majority of the patients with at least one $P$. aeruginosa positive culture (28 of $38,58 \%$ ) were previously characterised as chronically colonised (Table 2). The age distribution of the patients and culture results are presented in Table 3, and a surprisingly higher prevalence of $P$. aeruginosa was observed for the age group 5-10 years. $P$. aeruginosa was isolated from more than one sample from the same patient in 17 instances, but concomitant positive cultures from

Table 1. Distribution of samples and $P$. aeruginosa isolates

\begin{tabular}{lcc}
\hline Sample & $\begin{array}{c}\text { Number } \\
\text { collected }\end{array}$ & $\begin{array}{c}\text { P. aeruginosa- } \\
\text { positive }(\%)\end{array}$ \\
\hline Sputum & 135 & $53(39.3)$ \\
Throat swabs & 119 & $10(8.4)$ \\
Swabs of patients' hands & 254 & $2(0.8)$ \\
Swabs of medical staff hands & 240 & 0 \\
Total & 748 & $65(8.6)$ \\
\hline
\end{tabular}

Table 2. Previous bacterial colonisation and P. aeruginosa isolation from respiratory samples

\begin{tabular}{lcc}
\hline $\begin{array}{l}\text { Previous } \\
\text { colonisation }\end{array}$ & $\begin{array}{c}\text { Number of } \\
\text { patients (\%) }\end{array}$ & $\begin{array}{c}\text { P. aeruginosa- } \\
\text { positive }\end{array}$ \\
\hline Chronic & $48(50)$ & 28 \\
Intermittent & $30(31)$ & 8 \\
Not colonised & $18(19)$ & 2 \\
Total & 96 & 38 \\
\hline
\end{tabular}

Table 3. Age distribution and $P$. aeruginosa isolation from respiratory samples

\begin{tabular}{lcc}
\hline $\begin{array}{l}\text { Age } \\
\text { years })\end{array}$ & $\begin{array}{c}\text { Number of } \\
\text { patients }\end{array}$ & $\begin{array}{c}\text { P. aeruginosa- } \\
\text { positive }(\%)\end{array}$ \\
\hline $0-2$ & 10 & $2(20.0)$ \\
$2-5$ & 19 & $7(36.8)$ \\
$5-10$ & 33 & $16(48.4)$ \\
$10-15$ & 21 & $8(38.1)$ \\
$>15$ & 13 & $5(38.4)$ \\
Total & 96 & 38 \\
\hline
\end{tabular}

$\left(\chi^{2} ; 4\right.$ degrees of freedom; $\mathrm{p}$ value $\left.\cong 0.59\right)$. different sites were not observed. The two patients with positive hand swabs were infants, and $P$. aeruginosa was not isolated from respiratory samples from these patients. Hand samples from the medical staff were all negative for $P$. aeruginosa.

A total of $86 P$. aeruginosa strains was identified in the 65 positive samples. Mucoid strains were detected in 23 samples. The susceptibility of $P$. aeruginosa isolates to the antibiotics tested is presented in Table 4 . Resistance to the amikacin, carbenicillin and ciprofloxacin was significantly greater for mucoid strains $(\mathrm{p}<$ $0.05)$. Resistance to ceftazidime was similar for mucoid and non-mucoid strains (20\%). Three multiresistant strains $(3.4 \%)$ were isolated, two of them from the same patient on different occasions, with the same susceptibility pattern except for susceptibility to ceftazidime.

There were ten $\mathrm{CF}$ sibling pairs among the 96 patients studied, but $P$. aeruginosa was isolated from both children in only one sibling pair (two sisters). Five different strains were isolated on different occasions from these girls, each one with a particular pattern of susceptibility to antibiotics.

RAPD typing was performed on 83 isolates of $P$. aeruginosa and 51 distinct patterns were obtained (Figs. 1 and 2). P. aeruginosa isolates from the same patient usually had the same RAPD pattern; this was also observed with the isolates from the same sample with different morphology (mucoid, non-mucoid) or antimicrobial susceptibility. Some patients had more than one genotype during the period, e.g., patient LR (Fig. 2), who had four different genotypes and patient HY (Fig. 1), who apparently acquired a new strain as shown by the RAPD pattern of the last isolate (lane 14). RAPD results on the isolates from the two sisters revealed that they were colonised with different strains, but the isolates from each one had the same RAPD pattern (Fig. 2; NE and NA). There were two occasions when two patients gave organisms with the same RAPD pattern; they did not report social contact and the samples were collected on different days. RAPD typing of the three multiresistant strains showed different genotypes, even for the two isolates from the same patient.

\section{Discussion}

In this study, $P$. aeruginosa was isolated at least once from $39 \%$ of the patients during the 6-month period of surveillance, while retrospective analysis of medical records showed $50 \%$ of patients with chronic and $31 \%$ with intermittent colonisation. Although the proportion of colonised patients in the retrospective analysis is similar to that observed in many CF centres around the world [10,20,21], a lower prevalence of P. aeruginosa was observed in airway samples from the patients in 
Table 4. Antimicrobial susceptibility of $P$. aeruginosa isolates

\begin{tabular}{lccrr}
\hline & \multicolumn{3}{c}{ Number susceptibility/number tested (\%) } & \\
\cline { 2 - 4 } Antibiotic & Mucoid strains & Non-mucoid strains & Total & p value \\
\hline Amikacin* & $15 / 23(65.2)$ & $59 / 63(93.6)$ & $74 / 86(86.0)$ & $<0.01$ \\
Carbenicillin* & $18 / 23(78.26)$ & $60 / 63(95.2)$ & $78 / 86(90.6)$ & 0.03 \\
Cefoperazone & $11 / 15(73.3)$ & $40 / 48(83.3)$ & $51 / 63(80.9)$ & 0.46 \\
Cefotaxime & $15 / 23(65.2)$ & $43 / 63(68.2)$ & $58 / 86(67.4)$ & 1.00 \\
Ceftazidime & $18 / 23(78.2)$ & $52 / 63(82.5)$ & $70 / 86(81.3)$ & 0.76 \\
Ceftriaxone & $8 / 23(34.8)$ & $19 / 62(30.6)$ & $27 / 85(31.8)$ & 0.92 \\
Gentamicin & $14 / 23(60.9)$ & $51 / 63(80.9)$ & $65 / 86(75.5)$ & 0.10 \\
Imipenem & $19 / 23(82.6)$ & $59 / 63(93.6)$ & $78 / 86(90.6)$ & 0.20 \\
Pefloxacin & $2 / 5(40.0)$ & $6 / 14(42.8)$ & $8 / 19(42.1)$ & 1.00 \\
Ciprofloxacin* & $15 / 23(65.2)$ & $56 / 63(88.9)$ & $71 / 86(82.5)$ & 0.02 \\
Aztreonam & $20 / 23(86.9)$ & $59 / 63(93.6)$ & $79 / 86(91.8)$ & 0.38 \\
\hline
\end{tabular}

$* \mathrm{p}<0.05$ ( $\chi^{2}$ Yates corrected or Fisher's two-tailed exact tests).

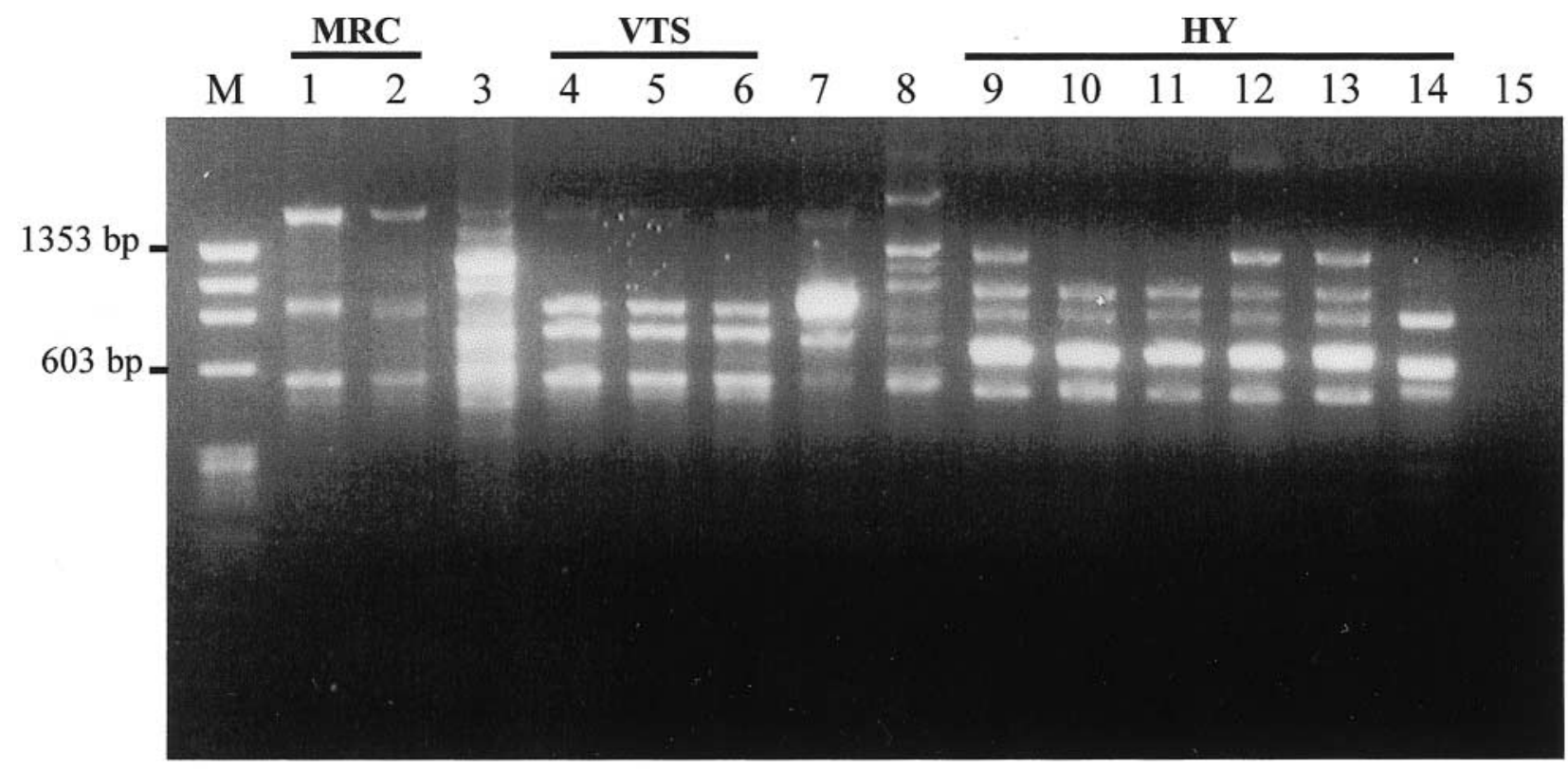

Fig. 1. Agarose $1.5 \%$ gel electrophoresis stained with ethidium bromide of RAPD products from P. aeruginosa isolates of CF patients. Lanes: M, mol. wt markers (PhiX174 RF DNA, HaeIII digest; Pharmacia, Uppsala, Sweden); upper case letters indicate patients' initials, randomly re-arranged; 15, negative control (no DNA added).

the present study. These results probably reflect the short period of observation, because the majority of patients were seen only once or twice in that period, and negative cultures can be obtained from patients with intermittent or even chronic colonisation.

The bacteriology of respiratory infections in $\mathrm{CF}$ has been well studied by several authors $[22,23]$ and some agree that there is good correlation between upper and lower respiratory tract colonisation [24, 25]. Indeed, sputum and throat cultures have been used world-wide to monitor and guide treatment of respiratory infections in CF patients. However, recent published data comparing oropharyngeal and quantitative bronchoalveolar lavage (BAL) cultures have concluded that oropharyngeal cultures do not reliably reflect lower respiratory tract infection [26, 27]. Nevertheless, most of the studies that evaluated the impact of bacterial colonisation on prognosis used oropharyngeal and sputum cultures for investigation [3], and the BAL criteria for the diagnosis of lower respiratory tract infection in CF were established only in 1994 [28]. Therefore, so far there is no information as to whether the BAL criteria have the same correlation with prognosis.

The isolation of $P$. aeruginosa from throat swabs (8.4\%) was significantly inferior to that obtained from sputum (39\%). This is not surprising and a lower prevalence of $P$. aeruginosa was expected in patients with less suppuration or younger age, but this probably also reflects the reduced sensitivity of the method for detection of $P$. aeruginosa. The low sensitivity of throat swab sampling is problematic, because early diagnosis and treatment of $P$. aeruginosa colonisation seems to delay chronic colonisation and to result in a better prognosis, and BAL samples are not simple to obtain routinely from these patients. These technical aspects of airway sampling have led some authors to investigate more sensitive techniques for $P$. aeruginosa detection, such as PCR [29-31], but this approach has never been tested on clinical grounds as a routine test. 


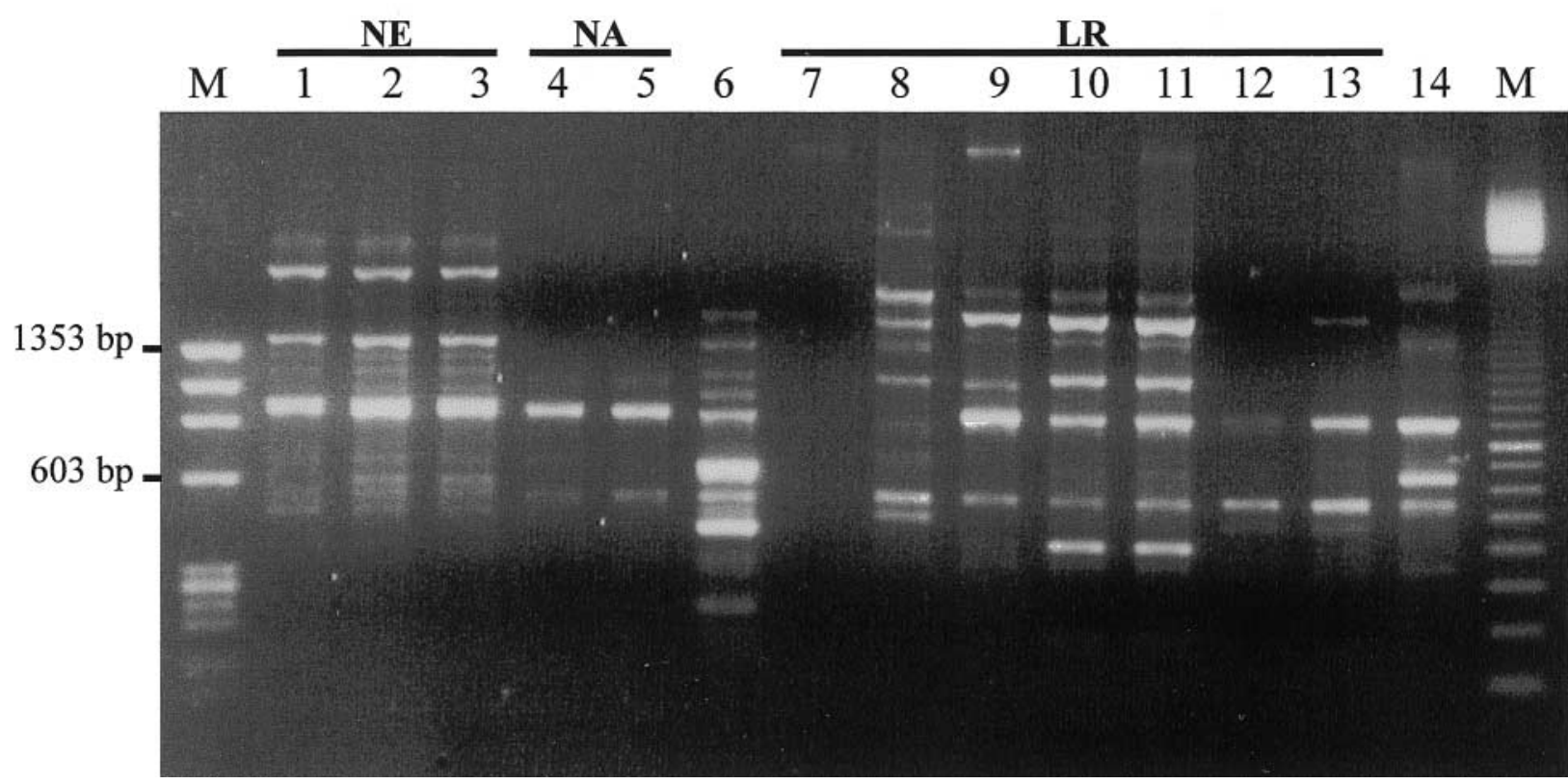

Fig. 2. Agarose $1.5 \%$ gel electrophoresis stained with ethidium bromide of RAPD products from $P$. aeruginosa isolates of CF patients. Lanes: M, mol. wt markers (PhiX174 RF DNA, Hae III digest and 100-bp ladder; Pharmacia); upper case letters indicate patients' initials, randomly re-arranged; 7, an isolate that did not result in RAPD products, classified as non-typable (NT); 15, negative control (no DNA added).

A trend was observed (although it was not statistically significant) of a higher prevalence of $P$. aeruginosa among younger patients, 5-10 years of age. This finding may be a consequence of delayed diagnosis in Brazil, with many patients referred to this hospital after the age of 5 years, when chronic $P$. aeruginosa colonisation had started in the first years of life. Delayed diagnosis has a major impact on prognosis and can also be the cause of premature death among patients with more severe disease (and a higher proportion of $P$. aeruginosa colonisation) causing this 'preponderance' of $P$. aeruginosa colonisation at younger ages. The fact that the prevalence of $P$. aeruginosa colonisation remained stable after the age of 10 years supports this hypothesis, because an increasing prevalence of $P$. aeruginosa would be expected with age. This result can also be viewed as an alert, because this clinic does not routinely employ aggressive treatment for the first colonisation of $P$. aeruginosa as suggested by some authors [32,33], and that may explain $P$. aeruginosa colonisation in younger children.

With regard to antibiotic susceptibility, a relatively low proportion of resistance to ceftazidime (19\%) was found, although this drug is our first line drug for the treatment of pulmonary exacerbation in P. aeruginosa colonised patients, always in addition to aminoglycosides. This result is similar to observations made at other CF centres [34], except for a British CF centre that recently reported epidemic spread of a $\beta$-lactamase-producing $P$. aeruginosa strain and, therefore, detected $70 \%$ resistance to ceftazidime [8]. However, the latter centre used to prescribe ceftazidime as monotherapy, and this could induce or select $\beta$ - lactamase-producing $P$. aeruginosa strains. Mucoid isolates from the patients in the present study showed higher resistance to several antibiotics than non-mucoid strains, which can be attributed to the presence of large amounts of alginate acting as a physical barrier to antibiotic diffusion, or to a colonisation of longer duration and greater exposure to antibiotics. Multiresistant $P$. aeruginosa strains were found on only three occasions $(3.4 \%)$, a rate lower than that reported by Saiman et al. [34], who identified $13.3 \%$ of multiresistant strains among 1296 isolates from $67 \mathrm{CF}$ centres.

RAPD typing characterised 51 genotypes among 83 isolates of $P$. aeruginosa. Isolates with different genotypes were not observed in the same sample even when different morphological appearances or susceptibility to antibiotics were present. These data suggest that antibiotic susceptibility and morphology of the colonies are not reliable means for typing or discriminating among $P$. aeruginosa strains, and genotyping is warranted for such purposes. P. aeruginosa strains from $\mathrm{CF}$ patients are particularly difficult to type; they are usually lipopolysaccharide-deficient and tend to lose the phage and pyocin typing responses due to phenotypic conversion $[11,12]$.

Indeed, genotyping has been used as the main tool for epidemiological studies of $P$. aeruginosa colonisation in CF patients. Techniques of DNA macro-restriction and pulsed-field or field inversion gel electrophoresis have been used in many studies to identify crossinfection between CF patients [35-37]. Although these techniques have high discriminatory power, they are expensive, difficult, and generally require a hybridisa- 
tion step. As a result, RAPD has emerged as a fast and simple PCR-derived technique with high discriminatory power, suitable for application in epidemiological studies [13, 16, 38, 39]. However, because of the low stringency conditions and the random features of the method, DNA extraction and quantification must be very well controlled to avoid amplification of spurious DNA and to maintain its reproducibility and reliability [40].

The results obtained with RAPD typing of the $P$. aeruginosa isolates were in keeping with the results described by other investigators $[11,13]$, as the persistence of one strain in each patient was observed throughout the study. Despite that, some patients had more than one genotype during the period studied, and one patient had four different genotypes. This clonal persistence of $P$. aeruginosa strains in CF patients was described previously during an 8-year follow-up by Römling et al. [11] and confirmed later by Mahenthiralingam et al. [13]. Although the typing method applied was different, both studies also reported few temporal changes in genotype patterns, which were attributed to re-arrangements in DNA structure or mutations, and perhaps these changes represent the genetic basis for conversion of $P$. aeruginosa strains to a common phenotype.

The method used by Mahenthiralingam et al. [13] was reproduced in this laboratory with similar results, although with fewer changes in RAPD profiles, perhaps because of the shorter period of observation.

Cross-infection between $\mathrm{CF}$ patients was investigated by several authors and identified between sibling pairs $[24,35]$ and patients with close social contact, such as those who attend CF summer camps [24, 36, 38, 41]. Multiresistant P. aeruginosa [5] and B. cepacia [7, 42] cross-infections were also identified. The implications of these findings were significant, and patient cohorting by colonisation status ensued in several CF centres world-wide $[9,10]$. Furthermore, in a recent publication Mahadeva et al. [43] reported earlier colonisation with $P$. aeruginosa among referred patients who were formerly cared for at specialised CF centres compared with those cared for by general practitioners, which could be attributed to a higher risk of cross-colonisation in CF centres. These findings were contested by Spencer [44], who supports the belief that the earlier colonisation reflects a major need for early detection of $P$. aeruginosa in CF centres, and that cross-colonisation is unusual in paediatric CF centres. In the present study, indistinguishable isolates were identified in different patients on only two occasions; these four patients did not report social contact and the samples were collected on different occasions. Furthermore, neither pair of patients ever shared a common room during hospital admissions, and these CF patients do not have common social activities like summer camps or physiotherapy sessions, suggesting that cross-colo- nisation, if it occurs, is rare in this outpatient clinic. This idea was reinforced by the small number of isolates on the hands of patients ( 2 of $254,0.8 \%$ ), the absence of $P$. aeruginosa on the hands of medical staff, and the finding of different genotypes among the three multiresistant strains.

The role of the inanimate environment as a route of $P$. aeruginosa transmission in CF patients is a matter of debate. Previous studies [45-47] could not identify $P$. aeruginosa reservoirs in hospital wards or found a small number of strains that were different from $\mathrm{CF}$ patients' isolates. However, Döring et al. [48] identified transmission of $P$. aeruginosa between CF patients and the inanimate environment (sink drains), in addition to contamination of the hands of patients and personnel in a paediatric ward. In the present study, a common source of $P$. aeruginosa acquisition seems unlikely, because a large number of genotypes was identified among the patients, but it cannot be ruled out because many of them were admitted to the hospital at least once. However, the small number of isolates from the hands of patients may be a consequence of the method of sampling (cotton swabs), because the method of hand immersion in saline solution used by Döring et al. [48] seems to be more sensitive.

In conclusion, the prevalence of $P$. aeruginosa in respiratory samples from these CF patients was $39 \%$. No $P$. aeruginosa cross-infection between patients was observed and no common source of acquisition was identified. RAPD typing characterised 51 genotypes among the 83 isolates of $P$. aeruginosa, and clonal persistence was observed in the majority of patients with more than one isolate. However, these results are the outcome of a short period of observation, and longer periods of surveillance are required to confirm them.

We thank the medical staff of the Paediatric Pulmonology Unit of the Instituto da Criança for their essential role in the enrolment of study patients and for their support. We also thank Dr Cláudio Sérgio Pannuti and colleagues at the Laboratory of Virology (Instituto de Medicina Tropical de São Paulo) for technical assistance and for encouraging and supporting this work. This work was supported by Fundação de Amparo à Pesquisa do Estado de São Paulo (FAPESP), grant no. 1995/00033-6. L.V.F. da S.F. is sponsored by CAPES, Brazil.

\section{References}

1. Govan JRW, Deretic V. Microbial pathogenesis in cystic fibrosis: mucoid Pseudomonas aeruginosa and Burkholderia cepacia. Microbiol Rev 1996; 60: 539-574.

2. Zach MS. Lung disease in cystic fibrosis - an updated concept. Pediatr Pulmonol 1990; 8: 188-202.

3. Ballmann M, Rabsch P, von der Hardt H. Long term follow up of changes in FEV1 and treatment intensity during Pseudomonas aeruginosa colonisation in patients with cystic fibrosis. Thorax 1998; 53: 732-737.

4. Kelly NM, Fitzgerald MX, Tempany E, O’Boyle C, Falkiner FR, Keane CT. Does Pseudomonas aeruginosa cross-infection occur between cystic fibrosis patients? Lancet 1982; 2: 688-690.

5. Pedersen SS, Koch C, Høiby N, Rosendal K. An epidemic spread of multiresistant Pseudomonas aeruginosa in a cystic 
fibrosis centre. J Antimicrob Chemother 1986; 17: 505-516.

6. Pedersen SS, Jensen T, Pressler T, Høiby N, Rosendal K. Does centralized treatment of cystic fibrosis increase the risk of Pseudomonas aeruginosa infection? Acta Paediatr Scand 1986; 75: $840-845$.

7. LiPuma JJ, Dasen SE, Nielson DW, Stern RC, Stull TL. Person-to-person transmission of Pseudomonas cepacia between patients with cystic fibrosis. Lancet 1990; 336: 1094-1096.

8. Cheng K, Smyth RL, Govan JRW et al. Spread of beta-lactamresistant Pseudomonas aeruginosa in a cystic fibrosis clinic. Lancet 1996; 348: 639-642.

9. Seibert KM, Weatherly M, Bell M. A national survey of infection control practices and respiratory pathogens at cystic fibrosis centers. Pediatr Pulmonol 1998; 17 Suppl: 306 (Abstract 366).

10. Frederiksen B, Koch C, Høiby N. Changing epidemiology of Pseudomonas aeruginosa infection in Danish cystic fibrosis patients (1974-1995). Pediatr Pulmonol 1999; 28: 159-166.

11. Römling U, Fiedler B, Bo $\beta$ hamer $\mathrm{J}$ et al. Epidemiology of chronic Pseudomonas aeruginosa infections in cystic fibrosis. $J$ Infect Dis 1994; 170: 1616-1621.

12. The International Pseudomonas aeruginosa Typing Study Group. A multicenter comparison of methods for typing strains of Pseudomonas aeruginosa predominantly from patients with cystic fibrosis. J Infect Dis 1994; 169: 134-142.

13. Mahenthiralingam E, Campbell ME, Foster J, Lam JS, Speert DP. Random amplified polymorphic DNA typing of Pseudomonas aeruginosa isolates recovered from patients with cystic fibrosis. J Clin Microbiol 1996; 34: 1129-1135.

14. Welsh J, McClelland M. Fingerprinting genomes using PCR with arbitrary primers. Nucleic Acids Res 1990; 18: 7213-7218.

15. Kerr JR, Moore JE, Curran MD et al. Investigation of a nosocomial outbreak of Pseudomonas aeruginosa pneumonia in an intensive care unit by random amplification of polymorphic DNA assay. J Hosp Infect 1995; 30: 125-131.

16. Adams C, Morris-Quinn M, McConnell F et al. Epidemiology and clinical impact of Pseudomonas aeruginosa infection in cystic fibrosis using AP-PCR fingerprinting. J Infect 1998; 37: $151-158$.

17. National Committee for Clinical Laboratory Standards. Approved standard M2-A5. Performance standards for antimicrobial disk susceptibility tests, 5th edn. Wayne, PA, National Committee for Clinical Laboratory Standards. 1993: 1-31.

18. Cystic Fibrosis Foundation. Microbiology and infectious diseases in cystic fibrosis. Consensus Conference: Concepts in Care, vol 5, section 1. Bethesda, MD, Cystic Fibrosis Foundation. 1994.

19. Sambrook J, Fritsch EF, Maniatis T. Molecular cloning: a laboratory manual, 2nd edn. Cold Spring Harbor, NY, Cold Spring Harbor Laboratory Press. 1989.

20. Høiby N. Epidemiological investigations of the respiratory tract bacteriology in patients with cystic fibrosis. Acta Pathol Microbiol Scand B Microbiol Immunol 1974; 82: 541-550.

21. Johansen HK, Kovesi TA, Koch C, Corey M, Høiby N, Levison H. Pseudomonas aeruginosa and Burkholderia cepacia infection in cystic fibrosis patients treated in Toronto and Copenhagen. Pediatr Pulmonol 1998; 26: 89-96.

22. Iacocca VF, Sibinga MS, Barbero GJ. Respiratory tract bacteriology in cystic fibrosis. Am J Dis Child 1963; 106: $315-324$.

23. Høiby N. Microbiology of lung infections in cystic fibrosis patients. Acta Paediatr Scand 1982; 71 Suppl 301: 33-54.

24. Thomassen MJ, Demko CA, Doershuk CF, Root JM. Pseudomonas aeruginosa isolates: comparisons of isolates from campers and from sibling pairs with cystic fibrosis. Pediatr Pulmonol 1985; 1: 40-45.

25. Ramsey BW, Wentz KR, Smith AL et al. Predictive value of oropharyngeal cultures for identifying lower airway bacteria in cystic fibrosis patients. Am Rev Respir Dis 1991; 144: $331-337$.

26. Armstrong DS, Grimwood K, Carlin JB, Carzino R, Olinsky A, Phelan PD. Bronchoalveolar lavage or oropharyngeal cultures to identify lower respiratory pathogens in infants with cystic fibrosis. Pediatr Pulmonol 1996; 21: 267-275.

27. Rosenfeld M, Emerson J, Accurso F et al. Diagnostic accuracy of oropharyngeal cultures in infants and young children with cystic fibrosis. Pediatr Pulmonol 1999; 28: 321-328.
28. Ramsey BW, Boat TF. Outcome measures for clinical trials in cystic fibrosis. Summary of a Cystic Fibrosis Foundation consensus conference. J Pediatr 1994; 124: 177-192.

29. O'Callaghan EM, Tanner MS, Boulnois GJ. Development of a PCR probe test for identifying Pseudomonas aeruginosa and Pseudomonas (Burkholderia) cepacia. J Clin Pathol 1994; 47: 222-226.

30. Karpati F, Jonasson J. Polymerase chain reaction for the detection of Pseudomonas aeruginosa, Stenotrophomonas maltophilia and Burkholderia cepacia in sputum of patients with cystic fibrosis. Mol Cell Probes 1996; 10: 397-403.

31. Da Silva Filho LVF, Levi JE, Bento CNO, Da Silva Ramos SRT, Rozov T. PCR identification of Pseudomonas aeruginosa and direct detection in clinical samples from cystic fibrosis patients. J Med Microbiol 1999; 48: 357-361.

32. Valerius NH, Koch C, Høiby N. Prevention of chronic Pseudomonas aeruginosa colonisation in cystic fibrosis by early treatment. Lancet 1991; 338: 725-726.

33. Vazquez C, Municio M, Corera M, Gaztelurrutia L, Sojo A, Victoria JC. Early treatment of Pseudomonas aeruginosa colonization in cystic fibrosis. Acta Paediatr 1993; 82: 308-309.

34. Saiman L, Mehar F, Niu WW et al. Antibiotic susceptibility of multiply resistant Pseudomonas aeruginosa isolated from patients with cystic fibrosis, including candidates for transplantation. Clin Infect Dis 1996; 23: 532-537.

35. Grothues D, Koopmann U, von der Hardt H, Tümmler B. Genome fingerprinting of Pseudomonas aeruginosa indicates colonization of cystic fibrosis siblings with closely related strains. J Clin Microbiol 1988; 26: 1973-1977.

36. Tümmler B, Koopmann U, Grothues D, Weissbrodt $H$, Steinkamp G, von der Hardt H. Nosocomial acquisition of Pseudomonas aeruginosa by cystic fibrosis patients. J Clin Microbiol 1991; 29: 1265-1267.

37. Talon D, Cailleaux V, Thouverez M, Michel-Briand Y. Discriminatory power and usefulness of pulsed-field electrophoresis in epidemiological studies of Pseudomonas aeruginosa. J Hosp Infect 1996; 32: 135-145.

38. Hoogkamp-Korstanje JAA, Meis JFGM, Kissing J, van der Laag J, Melchers WJG. Risk of cross-colonization and infection by Pseudomonas aeruginosa in a holiday camp for cystic fibrosis patients. J Clin Microbiol 1995; 33: 572-575.

39. Kersulyte D, Struelens MJ, Deplano A, Berg DE. Comparison of arbitrarily primed PCR and macrorestriction (pulsed-field gel electrophoresis) typing of Pseudomonas aeruginosa strains from cystic fibrosis patients. J Clin Microbiol 1995; 33: 2216-2219.

40. Tyler KD, Wang G, Tyler SD, Johnson WM. Factors affecting reliability and reproducibility of amplification-based DNA fingerprinting of representative bacterial pathogens. $J$ Clin Microbiol 1997; 35: 339-346.

41. Speert DP, Lawton D, Damm S. Communicability of Pseudomonas aeruginosa in a cystic fibrosis summer camp. J Pediatr 1982; 101: 227-229.

42. Govan JRW, Brown PH, Maddison J et al. Evidence for transmission of Pseudomonas cepacia by social contact in cystic fibrosis. Lancet 1993; 342: 15-19.

43. Mahadeva R, Webb K, Westerbeek RC et al. Clinical outcome in relation to care in centres specialising in cystic fibrosis: cross sectional study. BMJ 1998; 316: 1771-1775.

44. Spencer D. Clinical outcome in relation to care in centres specialising in cystic fibrosis. Cross infection with Pseudomonas aeruginosa is unusual. BMJ 1999; 318: 58.

45. Speert DP, Campbell ME. Hospital epidemiology of Pseudomonas aeruginosa from patients with cystic fibrosis. J Hosp Infect 1987; 9: 11-21.

46. Orsi GB, Mansi A, Tomao P, Chiarini F, Visca P. Lack of association between clinical and environmental isolates of Pseudomonas aeruginosa in hospital wards. J Hosp Infect 1994; 27: 49-60.

47. Zembrzuska-Sadkowska E, Sneum M, Ojeniyi B, Heiden L, Høiby N. Epidemiology of Pseudomonas aeruginosa infection and the role of contamination of the environment in the Danish Cystic Fibrosis Centre. J Hosp Infect 1995; 29: 1-7.

48. Döring $\mathrm{G}$, Jansen $\mathrm{S}$, Noll $\mathrm{H}$ et al. Distribution and transmission of Pseudomonas aeruginosa and Burkholderia cepacia in a hospital ward. Pediatr Pulmonol 1996; 21: $90-100$. 